\title{
A Muralha: (ainda) os bandeirantes e a identidade nacional na "festa" dos 500 anos 1
}

André Luís BERTELLI DUARTE²

Resumo:

O artigo apresenta uma investigação sobre a adaptação do romance A Muralha (Dinah Silveira de Queiroz, 1954) para a televisão, na minissérie homônima produzida pela Rede Globo no contexto de celebração dos 500 anos da chegada dos portugueses ao Brasil, em 2000. Revela-se como a ficção histórica compõe o universo simbólico das representações sociais em dois momentos em que se celebram efemérides que favorecem, politicamente, determinados grupos.

Palavras-chave: bandeirantismo; televisão; identidade nacional; romance histórico.

\section{A Muralha: (still) the bandeirantes and the national identity in the 500 year "party"}

\begin{abstract}
:
The article presents an investigation on the adaptation of the novel A Muralha (Dinah Silveira de Queiroz, 1954) for television, in the homonymous miniseries produced by Rede Globo in the context of the celebration of the 500 years of the arrival of the Portuguese in Brazil, in 2000. It reveals how historical fiction composes the symbolic universe of social representations in two moments in which ephemeris are celebrated that favor, politically, certain groups.
\end{abstract}

Keywords: bandeirantismo; TV; national identity; historical

\section{A Muralha: (aún) los bandeirantes y la identidad nacional en la "fiesta" de los 500 años}

\begin{abstract}
Resumen:
El artículo presenta una investigación sobre la adaptación de la novela A Muralha (Dinah Silveira de Queiroz, 1954) para televisión, en la miniserie homónima producida por Rede Globo en el contexto del 500 aniversario de la llegada de los portugueses a Brasil, en 2000. Revela cómo la ficción histórica compone el universo simbólico de las representaciones sociales en dos momentos en los que se celebran efemérides que favorecen políticamente a ciertos grupos.
\end{abstract}

Palabras clave: bandeirantismo; television; identidad nacional; romance historico.

\footnotetext{
${ }^{1}$ A pesquisa realizada conta com o fomento da Fundação de Amparo à Pesquisa de Minas Gerais (FAPEMIG).

2 Doutor em História pela Universidade Federal de Uberlândia (UFU). Professor de História do Colégio de Aplicação da Universidade Federal de Uberlândia (CAp/UFU). Pesquisador do Núcleo de Estudos em História da Arte e da Cultura (NEHAC/UFU).E-mail: andrebduarte@ufu.br.
} 


\section{Introdução}

Este artigo não visa tratar da construção histórica da figura do bandeirante, ou do que se convencionou chamar, mais recentemente, de mitologia bandeirante. ${ }^{3}$ Antes, procura compreender o processo de apropriação e de reconstrução desse arcabouço simbólico específico na adaptação do romance $A$ Muralha (Dinah Silveira de Queiroz, 1954) para a televisão, na minissérie homônima da Rede Globo, realizada por Maria Adelaide Amaral e por Denise Saraceni, no ano 2000. Além disso, entendo que as imagens e sentidos historicamente atribuídos aos bandeirantes paulistas passaram a integrar o conjunto mais amplo de referências do que se convencionou chamar identidade nacional, compreendida como projeto simbólico de integração de determinados valores e ideias-força que deveriam ser compartilhados por todos os habitantes da nação que, desde o século XIX, adquiriu feições diversas com interesses políticos e ideológicos específicos (ORTIZ, 1986).

A adaptação do romance para a televisão no contexto das celebrações oficiais dos 500 anos do Brasil trouxe para o plano nacional figuras e símbolos amplamente utilizados na construção do imaginário regional - identidade paulista -, o que, salvo melhor juízo, integrou um projeto político-cultural representado pelo governo do presidente Fernando Henrique Cardoso e pelo caráter imprimido por ele às celebrações do quinquicentenário da chegada dos portugueses ao Brasil.

Esta compreensão é central, em meu ponto de vista, para entendermos melhor: 1) o teor simbólico do passado presente nas narrativas construídas sobre os "500 anos do Descobrimento" e as suas possíveis relações com as forças políticas do presente, e 2) o papel exercido, no Brasil, pela televisão na construção de imagens e significados sobre a identidade política e cultural de seus habitantes.

A definição da celebração dos 500 anos e de seus produtos televisivos como objetos de investigação se deu em função do reconhecimento de que esse foi o último momento em que a televisão brasileira, notadamente a Rede Globo, exerceu uma hegemonia discursiva sobre a cultura e a identidade do país, que caracterizou a sociedade brasileira desde o início da década de 1970 (KEHL, 2018).

\footnotetext{
${ }^{3}$ Entendo mitologia bandeirante como "o conjunto de narrativas e tradições referentes à imagem do bandeirante como fundador da nacionalidade e enquanto símbolo do paulista" (SOUZA, 2007, p.151).
} 
Com efeito, vivenciamos, nas últimas duas décadas, a derrocada do modelo comunicacional que caracterizou a cultura de massas no século $\mathrm{XX}$, e que tinha na televisão sua forma mais acabada: um único centro de emissão de enunciados que eram captados por receptores em praticamente todos os lugares do país. Como ainda estamos começando a mapear e compreender esse processo, entendo inicialmente que ele é resultado de dois fenômenos congruentes: em primeiro lugar, a derrocada da televisão como meio de comunicação ocorre devido ao avanço e à disseminação de novas mídias (a internet, os canais de vídeo e streaming), que alteram tanto o modo de produção quanto o de consumo dos produtos audiovisuais; nesse modelo, a audiência passa a ter um papel ainda mais ativo na escolha daquilo que consome, de acordo com seus anseios e referenciais estéticos, temáticos, identitários dentre outros. Em segundo lugar, e não menos importante, vivenciamos nesse mesmo período a emergência de manifestações discursivas contra-hegemônicas (sobretudo de emancipação e divulgação cultural das minorias) que ficavam à margem da cultura de massas e que passaram a compor a cultura das mídias (devido também ao barateamento e facilitação da produção e divulgação de conteúdos). Esse processo alterou profundamente o teor das produções audiovisuais no Brasil, colocando em xeque a ideia de que existe uma "cultura nacional" apresentada e chancelada pela televisão.

O que pretendo demonstrar, portanto, é como na celebração dos 500 anos da chegada dos portugueses ao Brasil, no ano 2000, a produção da minissérie A Muralha tratou o tema da identidade nacional como algo pertencente a todos os brasileiros quando, de fato, a manipulava em favor de determinado grupo político-econômico por meio da apropriação do símbolo do bandeirante como fundador da nacionalidade. Isto nos permitirá ver com maior nitidez o papel dos meios de comunicação na composição social do imaginário histórico e de sua manipulação em favor de determinados interesses políticos.

Da página à tela: o romance e a adaptação para a televisão

Dinah Silveira de Queiroz publicou A Muralha em janeiro de 1954 em meio às celebrações do quartocentenário da cidade de São Paulo. O romance narra a história da família de Dom Braz Olinto, bandeirante experimentado, e de sua vida entre a propriedade de Lagoa Serena, a vila de São Paulo de Piratininga e o sertão. 
Ao longo da narrativa, Dinah Silveira de Queiroz assume uma perspectiva de contraponto entre os habitantes de São Paulo (os paulistas) e o povo do reino (Portugal), tomando o partido dos primeiros. Esse procedimento fica evidente na abordagem do conflito, ocorrido no início do século XVIII, entre os paulistas exploradores e os habitantes de outras capitanias e mesmo da metrópole pela posse das lavras de ouro, conhecido como Guerra dos Emboabas.

Alguns episódios conhecidos do conflito estão presentes em A Muralha: o início da sublevação emboaba contra os decretos de Borba Gato, liderada por Manuel Nunes Viana; o conflito no arraial da Ponta do Morro (atual Tiradentes/MG); o episódio do Capão da Traição, que marca a derrota das forças paulistas; e a recusa das mulheres da vila de São Paulo de Piratininga em aceitar os homens sobreviventes que retornam do conflito são narrados no romance de modo a destacar a vileza dos emboabas e o heroísmo dos(as) paulistas. O romance pode ser caracterizado como celebrativo e ufanista, pois é escrito e publicado como uma apologia ao caráter do(a) paulista num contexto de afirmação da identidade regional sob o viés da História.

A Muralha não foi a única apropriação do bandeirantismo como símbolo da identidade paulista nas celebrações dos quatrocentos anos de São Paulo, ao contrário, foi o principal vetor de identificação comunitária na metrópole. Para organizar as celebrações dos quatro séculos da criação do Colégio dos Jesuítas, o governo de São Paulo instituiu, em 1951, a Comissão do IV Centenário. Do trabalho dessa comissão surgiu, em 1952, o Parque do Ibirapuera, local que concentrou as atividades de comemoração do aniversário (dentre elas, várias Exposições sobre a História de São Paulo, a II Bienal de Arte, o Ballet do IV Centenário e outras), e onde foi inaugurado, no ano seguinte, o Monumento às Bandeiras, de Victor Brecheret. Em 1954, iniciaram-se os trabalhos de restauração da Casa do Bandeirante, no Butantã, lideradas pelo arquiteto Luiz Saia (SODRÉ, 2003).

O recurso ao bandeirantismo como força motriz da identidade de São Paulo remonta ao final do século XIX, quando fazendeiros do oeste paulista utilizam a imagem da expansão da fronteira agrícola (do café) como motor do desenvolvimento industrial do país em oposição ao atraso representado pelo império e por sua capital, o Rio de Janeiro. Essa associação está na origem da fundação do Partido Republicano Paulista que, após a proclamação da República, 
tornou-se protagonista do cenário político-econômico do país (ABUD, 2019; FUNARI, 1995; SOUZA, 2007).

Esse discurso político ganhou uma chancela intelectual e historiográfica mais nítida na década de 1920, quando historiadores e intelectuais como o já citado Afonso Taunay, Alfredo Ellis Júnior, Oliveira Viana e outros empreenderam pesquisas acerca da história bandeirante. Essas obras foram publicadas quando o predomínio paulista, político e econômico se encontrava em seu auge, e serviram para demonstrar que "o pioneirismo, o espírito de iniciativa, a bravura do fazendeiro cafeicultor, desbravando as matas para a nova cultura, implantando estradas de ferro, buscando nova mão-de-obra, eram a continuação das virtudes que os bandeirantes haviam possuído" (QUEIROZ, 1992, p. 82).

Ao longo do século XX houve um esforço de ampliação social desse imaginário, antes restrito à elite oligárquica do estado, sobretudo, durante a Revolução Constitucionalista de 1932. O conflito entre as forças do estado e as forças nacionais mobilizou, também no nível simbólico, o sentimento de pertencimento a uma coletividade por meio da recorrência à mitologia bandeirante. Nesse contexto, houve uma ampliação simbólica dessa mitologia para abarcar um universo social maior em torno de uma identidade única que pudesse unir São Paulo:

[...] então bandeirante passou a ser sinônimo de paulista, unindo ao significado histórico o significado geográfico. Todos os que se esmeravam em servir o movimento deflagrado atestavam que eram descendentes, senão na origem, pelo menos no espírito e nas virtudes, dos antigos sertanistas (QUEIROZ, 1992, p. 85).

A partir dessa ampliação simbólica da figura do bandeirante fica mais fácil compreender a ampla utilização desse imaginário nas comemorações do IV Centenário, em 1954, e, consequentemente, o sucesso popular do romance de Dinah Silveira de Queiroz, quando uma camada social muito mais ampla de leitores já podia se identificar com aquelas figuras apresentadas na trama.

De fato, A Muralha tornou-se um dos maiores sucessos editoriais da década de 1950, vendendo milhares de exemplares em mais de uma edição. O sucesso de público seria repetido quase meio século mais tarde, na adaptação do romance realizada pela Rede Globo em forma de minissérie, realizada por Maria Adelaide Amaral e dirigida por Denise Saraceni (MELLÃO, 
$2000)^{4}$. No horizonte, mais uma celebração: saem de cena os quatrocentos anos da cidade de São Paulo, entram os quinhentos anos do "Descobrimento" do Brasil.

A ideia de produzir uma adaptação do romance de Dinah Silveira de Queiroz para a televisão, levada a cabo pela Globo no ano 2000, surgiu no final de abril de 1999, quando Maria Adelaide Amaral foi chamada pelo diretor artístico da Rede Globo, Daniel Filho, para uma reunião que contou ainda com a participação dos dramaturgos Dias Gomes, Lauro César Muniz, Sérgio Marques e Ferreira Gullar. A ideia era que, para celebrar os 500 anos do Brasil, a emissora produziria cinco minisséries históricas para contemplar os cinco séculos de existência do país. Cada um dos autores manifestou o seu interesse para abordar um dos séculos, de modo que o século XVI teria "sobrado" para ela que, questionada por Daniel Filho sobre o que iria fazer, respondeu: "São Paulo - assim, sem muito pensar. Ele me perguntou o que seria São Paulo no século XVI, e respondi, sem pensar, A Muralha” (DWEK, 2005, p. 221-222).

É interessante observar que a associação imediata entre São Paulo e o bandeirantismo, feita por Maria Adelaide Amaral, não é fortuita. Nascida em Portugal em 1942, em uma família de ourives da região do Porto, ela emigrou para São Paulo justamente no ano de 1954, aos doze anos, período em que, como vimos, a exploração da figura do bandeirante como símbolo da identidade regional foi fartamente explorada pela cultura material, audiovisual, literária e histórica, ou seja, mesmo como imigrante, ela teve contato com a mitologia bandeirante, o que demonstra o poder das formas simbólicas na construção do imaginário individual e social.

Quando se debruçou sobre A Muralha, no entanto, Maria Adelaide Amaral percebeu que havia cometido um equívoco, pois a ação do romance histórico se passa no início do século XVIII e não no século XVI, como havia pensado. Logo, no entanto, percebeu que o problema poderia ser facilmente contornado:

Conservaria as personagens e a ideia central das tramas e mudaria o pano de fundo histórico. Ao invés de falar sobre as Minas Gerais e sobre a Guerra dos Emboabas, iria falar sobre o início do Movimento Bandeirista, ou seja, sobre aqueles homens que primeiro avançaram para o interior em busca de mão-de-obra indígena, quando o ouro ainda não era o objetivo principal (DWEK, 2005, p. 225).

\footnotetext{
${ }^{4}$ A Muralha obteve a maior audiência dentre todas as minisséries da Rede Globo do mesmo horário (23 horas). A estreia atingiu picos de 47 pontos no Ibope, sendo que a audiência média ficou em 34 pontos ao longo dos três meses de exibição (MELLÃO, 2000).
} 
Para dar fôlego ao enredo, Maria Adelaide Amaral e seus colaboradores João Emanuel Carneiro e Vicente Villari deram vida a novos personagens, exploraram os traços gerais dos já existentes no livro, e criaram e ampliaram tramas e situações. Por meio desse trabalho de ampliação do enredo, os autores abordaram temas que não faziam parte do romance, tais como a inquisição Ibérica (Dom Jerônimo Taveira), a conversão de judeus ao cristianismo e a imigração para o Brasil (Dona Ana), e a evangelização dos indígenas e os conflitos deflagrados com os bandeirantes contra a escravização dos nativos (os jesuítas Simão e Miguel, e a índia Moatira).

A mudança mais notável realizada no núcleo principal da trama foi feita no caráter de Tiago Olinto, que, diferentemente do romance, é dotado de uma "consciência cristã" tanto em relação às suas ações individuais quanto à violência praticada pelos seus contra os indígenas. Essa mudança, no entanto, partiu de uma demanda do produtor artístico do programa, Daniel Filho:

Percebi que estávamos sem herói, e não se pode contar uma história sem herói. Erro já cometido por mim em O primo Basílio. Era preciso que um dos personagens bandeirantes tivesse certa consciência em relação ao que estava acontecendo com os nativos, senão iríamos nos perder (FILHO, 2001, p. 102).

O delineamento do caráter heroico de Tiago Olinto, entretanto, não se deu somente através de sua consciência piedosa em relação à violência cometida contra o indígena, mas incluía também a expiação do pecado que cometeu ao engravidar Isabel, o que não poderia ser perdoado por sua esposa Beatriz (e pelo público de televisão que queria vê-los juntos) sem a devida remissão, que ocorre tanto com o seu arrependimento quanto com ações concretas (Tiago expia o pecado praticado ao construir, sozinho, a torre do sino da igreja da vila de São Paulo de Piratininga).

O trabalho de textura audiovisual de A Muralha foi coordenado por Denise Saraceni, que liderou uma grande equipe de produção artística. $\mathrm{O}$ tom geral adotado por ela foi a desglamourização da figura bandeirante. Com efeito, a equipe de produção criou um quadro geral onde os primeiros habitantes de São Paulo de Piratininga são pintados como homens e mulheres rudes, de maus modos, cuja vida material é marcada pela carestia. Tal perspectiva ia 
ao encontro de um desejo da produção em retratar o passado da forma mais verossímil possível, numa perspectiva realista, que envolveu grandes esforços na reconstituição de época. Antes do início das filmagens, toda a equipe assistiu a aulas e palestras com professores e escritores, como Eduardo Bueno, para compreender como era a sociedade da época. Uma especialista em usos e costumes, folclores e línguas, Iris Gomes da Costa, foi contratada para ajudar na ambientação histórica:

Além de traduzir os textos dos personagens indígenas para o tupi antigo, ela [Iris] adapta as falas para o chamado português castiço. Ensina o elenco a comer, sentar, tomar banho e até transar em cena, como se fazia no Brasil dos idos de 1600. Segundo Iris, há licenças por se tratar de uma obra de ficção. "Naquela época ninguém se tocava ou fazia sexo naturalmente, mas as cenas estão bem feitas" (FRANÇA, 2000, p. 05).

Todo o cuidado e investimento na ambientação histórica do romance, visível em $A$ Muralha, contribuem para criar um efeito de verdade, verossímil e vivaz, que, em nosso entendimento, concorre para o surgimento de uma determinada interpretação histórica. Ao romper a mediação entre o presente e o passado e, portanto, criar a ilusão de que o telespectador está vendo a história diante dos seus olhos, a minissérie traz consigo uma interpretação do passado totalizadora, numa perspectiva que apresenta uma determinada interpretação possível como verdadeira, portanto, impassível de ser questionada pelo telespectador. Mas quais elementos do passado presentes em A Muralha são representados como verdade histórica? Quais são os possíveis sentidos políticos dessas representações naquele contexto?

\section{A historicidade das representações do passado em $A$ Muralha}

Para dar contornos mais precisos ao pano de fundo histórico da minissérie, Maria Adelaide Amaral recorda que percorreu vários sebos da cidade de São Paulo e leu muita coisa. Nas pesquisas ela teve contato com obras historiográficas de diferentes temporalidades, que tratavam o tema com diferentes intencionalidades. Esse caráter "híbrido" da historiografia do bandeirismo paulista é o que dá o tom da interpretação histórica presente em A Muralha: se, por um lado, ela contribui para questionar o legado (e a mitologia) bandeirante, por meio da abordagem da violência e da escravização cometidas e da consequente defesa das culturas e das 
identidades indígenas, por outro, ela acaba por reforçar a imagem do bandeirante como arauto da nacionalidade brasileira pela sua luta contra a dominação estrangeira. Vejamos como essa interpretação "híbrida" é construída teledramaturgicamente.

No dia 04 de janeiro de 2000, a primeira cena de A Muralha exibia uma tela preta com o letreiro "Primeiros anos do século XVII, Brasil", para situar o telespectador a respeito da temporalidade e da localidade das ações que se desenrolariam na tela, naquele horário, pelos próximos meses. A seguir, uma tomada aérea partia do litoral de São Paulo em traveling até o alto da serra do Mar. Na sequência, eram apresentadas imagens da Mata Atlântica, de sua fauna e sua flora, ambiente onde surge uma aldeia habitada por povos indígenas que vivem em harmonia com o meio e com seus semelhantes (crianças brincam no rio, homens produzem suas flechas, mulheres preparam os alimentos colhidos). Corte. Abrindo caminho na mata com foices, aparecem homens rústicos paramentados com roupas de couro, chapéus e armas de fogo; mais adiante, observam acobertados pela mata o cotidiano harmonioso da vida na aldeia. Aquele que aparenta ser o líder do grupo sugere uma abordagem comercial (do tipo "dez índias por um espelho"), o outro julga mais fácil atacá-los e fazê-los prisioneiros: faz mira na pistola e atinge o crânio de um índio adulto no centro da aldeia, o sangue jorra e o corpo cai. Os demais indígenas se reúnem, alarmados. $\mathrm{O}$ ataque tem início e termina com a destruição da aldeia e o aprisionamento dos sobreviventes.

A sequência inicial da minissérie parece não deixar dúvidas quanto à abordagem escolhida pelos seus autores a respeito do tema do bandeirantismo: ao deslocar a trama do século XVIII para o início do século XVII, a equipe da minissérie fatalmente teria que abordar o tema do apresamento e da escravização do indígena, e o fez sem qualquer perspectiva de heroicização da figura bandeirante; ao contrário, não hesita sobre quem eram os algozes e quem eram as vítimas naquele processo histórico representado.

A questão indígena tem, com efeito, um papel central na minissérie A Muralha. Um esforço significativo foi realizado para reconstituir, em detalhes, o modo de vida dos primeiros habitantes do planalto brasileiro, não apenas do ponto de vista material, como também cultural. A abordagem é substancialmente distinta do romance de Dinah Silveira de Queiroz, onde os indígenas aparecem muito timidamente incorporados à empresa colonial na condição natural 
de escravizados, juntamente com alguns (poucos) africanos também escravizados. Numa das poucas passagens do livro onde há uma descrição dos costumes indígenas, a autora escreve:

De repente, Leonel começou a perceber, do outro lado, as plantações que denunciavam o pequeno arraial de índios, vindos das mais desencontradas paragens e que se reuniam sob o mando de Apingorá, que lhes ensinara os benefícios de sua experiência na agricultura dos brancos e até da sua religião. Era um misto de selvageria e de civilização, aquele aglomerado humano (QUEIROZ, 2000, p. 184, grifo nosso).

Note-se que os costumes indígenas, como a agricultura e a religião, são avaliados como positivos na medida em que foram ensinados pelos brancos no tempo em que Apingorá viveu como escravo de Dom Braz, ou seja, a escravização e a catequização trouxeram consequências positivas (civilização) para aqueles povos "selvagens". Na minissérie, a abordagem muda de tom completamente. Por um lado, a violência do apresamento e a escravização dos indígenas são interpretadas como práticas negativas, pois simbolizam a destruição de corpos, de saberes e de culturas vivas e complexas. São vistas, em última análise, como perdas na história do Brasil. Por outro lado, a catequização é interpretada também como uma violência, uma forma de extermínio cultural.

Entre a escrita do livro e a produção da minissérie temos que considerar as mudanças interpretativas que ocorreram, no âmbito da historiografia, tanto no que se refere aos significados do bandeirismo quanto à visão sobre os povos indígenas. Demonstrei anteriormente como a historiografia paulista do início do século XX foi decisiva para a construção de uma interpretação positiva sobre o bandeirantismo, visto como determinante para a ampliação das fronteiras nacionais e para a colonização e exploração do território. Por outro lado, há na historiografia brasileira avaliações sobre o bandeirismo que enfatizam o seu caráter negativo, violento e desagregador.

Tal visão já era presente no século XIX, notadamente na obra de Capistrano de Abreu, que enfatiza em seus Capítulos de História Colonial a violência da escravização indígena (SOUZA, 2007; DAVIDOFF, 1982). Mas é na segunda metade do século XX que a imagem crítica à empresa bandeirante torna-se mais recorrente e comum, a partir de trabalhos de intelectuais e historiadores como Viana Moog, Darcy Ribeiro, Sérgio Buarque de Holanda, 
Kátia Abud e John Manuel Monteiro. Tais trabalhos têm o mérito de compreender a atuação bandeirante num contexto de disputas e enfrentamentos com outros povos que habitavam o território, a partir das quais se deu a escravização sistemática dos povos derrotados, inclusive para obter ganhos comerciais.

Este processo de revisão crítica do heroísmo e do pioneirismo bandeirante foi fortalecido ainda pela emancipação política dos povos indígenas organizados, que ganhou notoriedade nos debates que precederam a elaboração da Constituição Federal, na segunda metade da década de 1980. O texto final, de 1988, reconheceu o direito originário dos indígenas às terras que tradicionalmente ocupam, bem como o usufruto dos recursos naturais e minerais presentes nelas. Além disso, reconheceu, pela primeira vez, o direito à diferença cultural, religiosa e linguística, a partir do entendimento de que o Brasil é um país composto por muitas culturas. A abordagem da questão indígena pela minissérie é, portanto, depositária das mudanças de compreensão sobre os povos e as culturas habitantes do Brasil.

O reconhecimento das culturas indígenas como parte integrante fundamental da cultura brasileira também promoveu mudanças sensíveis no modo de compreender os projetos missionários religiosos desenvolvidos entre as populações indígenas, assunto abordado em $A$ Muralha. Na minissérie, o tema da evangelização dos indígenas pelos padres missionários adquire um relevo considerável. Maria Adelaide Amaral cria dois personagens que são padres jesuítas, Simão e Miguel. Integrados à vida de São Paulo do Piratininga, eles apresentam grande resistência às expedições de apresamento de Dom Braz.

Um olhar mais atento, no entanto, percebe nuances na construção dos personagens que remetem a um debate profícuo sobre os significados da prática missionária. Padre Simão e padre Miguel são apresentados ao telespectador como mestre e discípulo. Ao longo da trama, porém, são evidenciadas as diferenças de concepção sobre o projeto missionário entre os dois: padre Simão representa o projeto missionário de aculturação, que deseja proteger os indígenas da violência colonial por meio de seu aldeamento e conversão ao catolicismo; padre Miguel, por sua vez, acredita que os indígenas devem preservar seus modos de vida tradicionais e manter suas crenças religiosas. A tensão criada pelas visões antagônicas dos dois padres vai se acirrando na medida em que padre Miguel se sente cada vez mais atraído pela índia Moatira. 
Quando a doença que dizima os gentios (gripe) se alastra pela vila e atinge mortalmente Moatira, o jovem padre confronta seu mentor:

Padre Simão: Por causa de Moatira, vosmecê se perdeu.

Padre Miguel: Não. Por nossa causa ela está perdida. Por nossa obsessão em querer moldá-los à nossa imagem e semelhança. Por que nós lhes impomos nosso deus, nosso modo de vida.

Padre Simão: O que vosmecê está a dizer?

Padre Miguel: Nós os protegemos dos paulistas, mas destruímos a harmonia do gentio, padre. Transformamos guerreiros em plantadores de mandioca. Retiramos seu orgulho, cobrimos seu corpo e, finalmente, nós o matamos com as nossas doenças;

Padre Simão: Isso que vosmecê está a dizer é uma heresia!

Padre Miguel: É por isso que nós temos medo do Caraíba. Porque ele diz o que somos e o que estamos a fazer com o gentio. Porque ele nos faz lembrar que existem outros deuses, existem outras crenças, padre! Porque ele retira nossa sapiência e revela o que somos.

Padre Simão: O quê?

Padre Miguel (repetidamente): Invasores! Assassinos!

(AMARAL; SARACENI, 2000).

Após o embate decisivo, padre Miguel conduz o corpo de Moatira até a aldeia de Caraíba para dar a ela um "enterro indígena" (seu corpo é pintado, enfeitado com penas e sepultado sentado em uma urna funerária de cerâmica, nos modos de rituais funerários tradicionais de povos Tupi-Guarani). O episódio marca, na trama, o rompimento de Miguel com a ordem dos jesuítas, com as atividades missionárias do Colégio, e a sua inserção no universo xamânico, sob a tutela de seu novo mestre, Caraíba.

A "conversão" do padre Miguel na narrativa demonstra que, apesar do esforço em "retratar como as coisas eram", a minissérie era capaz de discutir aspectos de seu tempo presente. A reflexão crítica sobre as consequências da evangelização missionária para os povos indígenas é muito mais pertinente ao contexto de produção e exibição da minissérie do que do objeto da representação, isto é, o Brasil do início do século XVII. Ela ganha fôlego, entre os católicos, sobretudo após o Concílio Vaticano II, que, por meio da encíclica Gaudim et Spes, apontou para a necessidade de mudanças nos projetos missionários, no sentido de valorização das culturas indígenas (FREIRE; OLIVEIRA, 2006, p. 148).

No Brasil, a perspectiva de mudanças no projeto missionário católico junto aos indígenas - que se caracterizou historicamente pelas ideias de aculturação e assimilação - 
tomou proporções institucionais com a criação do Conselho Indigenista Missionário (CIMI), em 1972. Em plena vigência dos anos de chumbo da ditadura militar, do "milagre brasileiro" e da construção da rodovia transamazônica (que ameaçou e desestruturou diversas comunidades indígenas), missionários católicos ligados à Teologia da Libertação foram perseguidos por forças conservadoras da Igreja e do governo militar, por denunciar a violência sistemática da qual as populações eram vítimas. Foi nesse contexto que se fortaleceu a perspectiva do trabalho missionário que caracterizaria a atuação católica nas décadas seguintes, onde:

o ideal de "encarnação" transformou-se na "inculturação" missionária, sintetizada na expressão "missão calada", na qual era valorizada a inserção no dia-a-dia da comunidade indígena. As práticas missionárias de defesa das terras indígenas, da cultura e da autodeterminação desses povos seriam guiadas pela "encarnação" e pela "conscientização". A "encarnação" era uma opção que visava à superação do etnocentrismo e do colonialismo. (FREIRE; OLIVEIRA, 2006, p. 151).

A representação das figuras missionárias católicas na minissérie A Muralha possui, portanto, uma atualidade evidente. Padre Miguel representava o novo projeto missionário progressista gestado pelo CIMI, ao passo que padre Simão representava a perspectiva missionária conservadora da catequização e da aculturação (“AS PORTAS...”, 2020). ${ }^{5}$ Por meio da representação histórica, a minissérie fazia a defesa pública do direito dos povos indígenas de manterem suas tradições, seus costumes e suas crenças.

Paralelamente à trama que envolveu o debate sobre os projetos missionários e a defesa da autonomia das culturas indígenas, os autores da minissérie abordaram também o conflito entre os paulistas e os habitantes do reino pela exploração do ouro. Na televisão, a oposição que Tiago Olinto representa à violência e escravização dos indígenas torna-o um bandeirante diferente, com uma outra dimensão temporal. Por isso, parte dele a iniciativa de pesquisar as riquezas minerais do território e a consequente descoberta do ouro de Ribeirão Dourado. Cedendo à vontade do filho, Dom Braz solicita ao governador (representante do rei de Portugal) a licença para explorar o ouro do local, no que tem a oposição vil de Dom Jerônimo e Bento

\footnotetext{
${ }^{5}$ No momento em que escrevo este texto, notícias em portais alternativos dão conta do assédio realizado por missões religiosas a indígenas isolados na Amazônia. Apesar da denúncia sistemática dos indígenas (que possuem o direito à autodeterminação garantido pela Constituição Federal), grupos como o Missão Novas Tribos, de missionários evangélicos, continuam promovendo novas ofensivas (“AS PORTAS...”, 2020).
} 
Coutinho, que armam para tomar para si a concessão. A disputa pela posse do veio de Ribeirão Dourado traz à vila de São Paulo de Piratininga o governador da província, Dom Diogo. Na cena da audiência em que anuncia a sua decisão, ocorre o seguinte diálogo:

Dom Diogo (diante da audiência, dirigindo-se à Dom Jerônimo): O que diria se eu dissesse que o veio pertence à Coroa?

Dom Jerônimo: Eu diria... Seja feita a vossa vontade, assim na Terra como no Céu! E me curvaria diante da vossa sábia decisão porque, ainda que isso contrariasse os meus interesses particulares, os interesses da Coroa se sobrepõem a todos os demais.

Dom Braz (interferindo rispidamente): Eu diria à vossa excelência que só matando a mim e a toda a minha família a Coroa vai tomar o que me pertence! Porque já é muito dar um quinto do ouro, às duras penas lavrados, para sustentar os luxos del-Rei do outro lado do mar! Eu vos diria que é muito dar uma parte do que produzimos e possuímos, e que esse é mais um ato de rapina, como muitos, como tantos outros que a Coroa nos tem feito. E que mais..

Dom Diogo: Vosmecê não diria mais nada. Porque eu acabo de decidir com quem vai ficar o veio... Ribeirão Dourado pertence à Dom Jerônimo Taveira. Tiago Olinto: Vossa Excelência está cometendo uma grande injustiça! Dom Braz: Então foi esse o juiz que a Coroa nos mandou. [...] Eu só respeito a autoridade de quem a exerce com equidade, não ao sabor dos seus caprichos! [...] Não percebem que ele veio à Piratininga para mostrar quem manda nesta terra e botar os paulistas no seu devido lugar? (AMARAL; SARACENI, 2000).

A mudança de foco do bandeirismo de apresamento (que marcou o início da minissérie) para o bandeirismo pesquisador de riquezas (que caracteriza o seu fim) promove a alteração do status do bandeirante de vilão para herói no processo histórico. A defesa do território, o elogio do trabalho, da conquista pelo esforço feita em oposição ao luxo, à rapinagem e, finalmente, à injustiça representados pela Coroa portuguesa, tornam os bandeirantes os primeiros brasileiros a defender a legitimidade da distinção entre os interesses dos "brasileiros" e os interesses do reino. Esse sentimento é transubstanciado em ação guerreira, na luta pela posse "justa" de Ribeirão Dourado, que forja com ainda maior profundidade a imagem do bandeirante como arauto da brasilidade.

Não é difícil notar que a minissérie $A$ Muralha opera com discursos contraditórios em seu enredo: a defesa que Dom Braz faz diante da injustiça praticada pelo representante da Coroa, que deseja apenas a exploração de seu trabalho para o enriquecimento alheio, poderia muito bem ser feita por algum personagem indígena (Apingorá, por exemplo) contra as 
injustiças praticadas pelos próprios bandeirantes. No entanto, um olhar mais atento para o contexto de exibição da minissérie revela que essa contradição básica está no centro do discurso oficial da história do Brasil, e que a minissérie é, em última análise, concordante com suas premissas básicas.

Nas comemorações dos 500 anos do Descobrimento, realizadas no ano 2000, o Estado teve um papel preponderante, a partir da execução do projeto "Brasil mais quinhentos". Em 22 de abril daquele ano, em Porto Seguro, Bahia, representantes do Brasil e de Portugal, bem como membros da Igreja e da sociedade civil organizada, celebraram os 500 anos da chegada de Pedro Álvares Cabral com um discurso fortemente marcado pela integração. Em sua intervenção, o então presidente da República Fernando Henrique Cardoso recordou os marginalizados da História (os indígenas, os negros e os sem-terra, dentre outros) e reforçou o papel do Estado como agente promotor de desenvolvimento econômico e justiça social (FRIGHETTO, 2005). Em seu discurso, não transparece a contradição de que, historicamente, esse mesmo Estado é o principal agente de marginalização econômica e social. Ou melhor, a contradição aparece, mas é escamoteada sob o discurso da integração nacional, de que o Estado é o reflexo da vontade de todos, desprovido, portanto, de interesses de classe.

Ao longo do século XX, o imaginário bandeirante também serviu para a promoção de um ideal de Estado como agente de integração e expansão nacional, no sentido que o Estado nacional encarnaria os princípios bandeirantes historicamente conhecidos (desenvolvimento econômico, ampliação e defesa de fronteiras, integração de populações ao projeto socioeconômico hegemônico) (DAVIDOFF, 1982). Há, portanto, uma afinidade eletiva entre a apropriação simbólica do bandeirantismo na minissérie $A$ Muralha e a perspectiva oficial dos 500 anos encampada pelo governo à época. Além disso, devemos recordar que FHC, apesar de ter nascido no Rio de Janeiro, teve sua carreira intelectual e política construída em São Paulo, onde participou da criação do Partido da Social Democracia Brasileira (PSDB), partido umbilicalmente ligado à elite paulista. $\mathrm{O}$ seu governo representaria, assim, o retorno do ideal de São Paulo como motor da história do Brasil, que tem no bandeirante a sua figura de proa. ${ }^{6}$

\footnotetext{
${ }^{6}$ Emir Sader chegou a afirmar, em artigo publicado na revista Carta Maior, que a eleição de Fernando Henrique Cardoso representou o acerto de contas da elite de São Paulo com a Federação após a derrota na Revolução Constitucionalista de 1932, e o consequente retorno do projeto hegemônico paulista da Primeira República (SADER, 2010).
} 


\section{Considerações finais}

Por tudo o que foi apresentado, podemos concluir que as representações do passado criadas pela minissérie $A$ Muralha, apesar do seu esforço de recriação histórica na perspectiva do realismo, remetem muito mais às questões do seu tempo presente, encetando em seu bojo algumas das contradições sociais mais latentes no contexto de representações dos 500 anos. Contudo, a própria minissérie dilui essas contradições e opta pela defesa da integração nacional, perspectiva em que afina e ressoa o discurso do poder.

A segunda metade do século XX foi marcada, no Brasil, pela hegemonia da televisão como veículo de comunicação e entretenimento. A integração nacional via televisão ganhou força decisiva a partir da expansão da rede de emissão de sinais e transmissão na década de 1970. Nesse processo, a Rede Globo exerceu, senão um monopólio, uma influência significativa sobre a informação e a sensibilidade de milhares de brasileiros, chegando mesmo a determinar os caminhos eleitorais do país (BUCCI; KEHL, 2004).

Essa influência voltou a ser sentida no contexto das reflexões sobre os significados dos "500 anos do Descobrimento", quando a Globo teve também um papel destacado com diversos produtos televisivos produzidos na e para a ocasião. De modo geral, a Globo abraçou o tom celebrativo oficial ditado pelo governo federal e suas representações, que tinham como elemento central a exaltação do papel do Estado na promoção de desenvolvimento econômico, justiça social e integração nacional. Analisei como a minissérie A Muralha se apropriou da mitologia bandeirante e a ressignificou de acordo com as premissas do Estado e dos grupos sociais que o representavam naquele momento, notadamente, a elite de São Paulo.

Desde a exibição da minissérie, vivenciamos alterações profundas nos modos de produção e consumo de mídia, de modo que a televisão vem perdendo sua potência discursiva. A emergência de ferramentas midiáticas mais acessíveis impulsionou a criação e a circulação de discursos contra-hegemônicos que concorreram para a desintegração de uma dada identidade nacional, forjada por longos anos de hegemonia da televisão e dos grupos sociais aos quais ela historicamente se vincula. Ainda estamos só começando a viver as consequências e a compreender as possibilidades desse processo. 


\section{Referências}

ABUD, Kátia. O sangue itimorato e as nobilíssimas tradições: a construção de um símbolo paulista, o bandeirante. Cuiabá: Ed. UFMT, 2019.

AMARAL, Maria Adelaide; SARACENI, Denise. A Muralha. Rio de Janeiro: Rede Globo, 2002. [Minissérie adaptada do romance A Muralha, de Dinah Silveira de Queiroz].

"AS PORTAS ESTÃO ABERTAS": indígenas denunciam missionários por ameaça contra povos indígenas isolados. Survival, 12 mar. 2020. Disponível em: https://www.survivalbrasil.org/ultimas-noticias/12356. Acesso em: 23 mar. 2020.

BUCCI, Eugênio; KEHL, Maria Rita. Videologias: ensaios sobre televisão. São Paulo: Boitempo, 2004.

DAVIDOFF, Carlos. Bandeirantismo: verso e reverso. São Paulo: Editora Brasiliense, 1982.

DWEK, Tuna. Maria Adelaide Amaral: a emoção libertária. São Paulo: Imprensa Oficial do Estado de São Paulo, 2005.

FILHO, Daniel. O circo eletrônico: fazendo TV no Brasil. São Paulo: Zahar, 2001.

FRANÇA, Carla. As profissões inusitadas das tramas de época. O Estado de S. Paulo, São Paulo, p. 5, 13 fev. 2000.

FREIRE, Carlos Augusto da Costa; OLIVEIRA, João Pacheco de. A presença indígena na formação do Brasil. Brasília: MEC, 2006.

FRIGHETTO, Gisele Novaes. Imagens do Brasil: análise do nacionalismo na adaptação de um romance histórico para a televisão. 2005. Dissertação (Mestrado em Ciências Sociais) Programa de Pós-Graduação em Ciências Sociais, São Carlos, UFSCar, 2005.

FUNARI, Pedro Paulo. A cultura material e a construção da mitologia bandeirante: problemas da identidade nacional brasileira. Ideias, Campinas, São Paulo, n. 1, p. 29-48, jan./jun. 1995.

KEHL, Maria Rita. Bovarismo brasileiro. São Paulo: Boitempo, 2018.

MELLÃO, Gabriela. A Muralha. Isto é... gente, São Paulo, 17 jan. 2000.

ORTIZ, Renato. Cultura brasileira e identidade nacional. São Paulo: Brasiliense, 1986.

QUEIROZ, Dinah Silveira de. A Muralha. Rio de Janeiro: Record, 2000.

QUEIROZ, Maria Isaura Pereira de. Ufanismo paulista: vicissitudes de um imaginário. Revista Usp, São Paulo, n. 13, p. 78-87, 1992. 
SADER, Emir. 1932: revolução ou golpe? Carta Maior, 26 abr. 2010. Disponível em: https://www.cartamaior.com.br/?/Blog/Blog-do-Emir/1932-revolucao-ou-golpe-/2/23819. Acesso em: 30 mar. 2020.

SODRÉ, João Clark A. A casa bandeirista de Luís Saia no IV Centenário de São Paulo: restauração e preservação da identidade paulista. In: Seminário Nacional DOCOMOMO, 5, 2003, São Carlos. Anais [...]. São Carlos: DOCOMOMO, 2003. p. 1-12. Disponível em: https://docomomo.org.br/wp-content/uploads/2016/01/070R.pdf. Acesso em: 30 mar. 2020.

Submetido em: 29.04.2020.

Aprovado em: 16.06.2021. 